\title{
Study on the Employability Structure and Evaluation of Business Students
}

\author{
Huibin Cui ${ }^{1}$; Ruyu Zhu ${ }^{1}$, Qianyao Huang ${ }^{1}$ \\ ${ }^{1}$ South China Normal University, Economics and Management, Guangzhou, Guangdong, China, \\ 510006 \\ hunter2011@foxmail.com
}

Keywords: Business Students; Employability; Labor Market; Effact factors

\begin{abstract}
Employability not only refers to the first time be hired ability, but also should include future career development of the relevant quality employee. Based on the data of University Business Majors, this paper used the AHP structural to analyze characteristics of college students the ability to employ. Business students' employability competencies include four dimensions of basic ability, psychological quality, professional knowledge and skills, Yuan skills. Yuan skills are the key element of which affect the ability to form Students may employ, followed by professional knowledge and skills, psychology and basic skills and Yuan skills need to be improved. At the same time, professional knowledge and skills is weak and all of those are not conducive to the initial employment and career development of college students.
\end{abstract}

\section{Introduction}

In recent years, employment of college students has become a hot topic of public concern. Since 2001, the number of Chinese college graduates year after year, is expected to total national college graduates in 2015 will reach 749 million, an additional 22 million more than in 2014. The employment units no major changes to the structure of demand for talent, resulting in an imbalance of supply and demand of graduate and employers, students' employment situation is grim, has been a common concern of all sectors of society.

Employability ability and employability are two different concepts. Employability refers to the individual ability to obtain a series of initial employment, and employability means an individual has the ability to get jobs, maintain employment and re-employment, and in the workplace can make all kinds of excellent quality performance, covering the initial employability and future competence two categories. In the current society, young people must have a set of core work skills (such as interpersonal skills, problem solving and teamwork, etc.) to effectively promote employment, but also must have sufficient skills to meet the increasingly complex demands of labor . With social change and industrial upgrading, and human resources are the most productive elements initiative. Both for the individual or the employer enterprise, employability skills are increasingly becoming a key source of competitive advantage. Currently, the ability to hire the deepening of research, were investigated from different dimensions, we can find the key factors that affect the ability to hire, to further enhance the ability of individuals to employment, alleviate structural difficulties that exist in employment for college students.

\section{Hypothesis and variable design}

According to the definition of employment capacity can be seen, the ability to be hired is constituted by the initial employability and ability to progress both at work, not only it refers to (namely the ability to get a job) is the ability for the first time employment should also include employee future Related quality of career development. Due to the different ability can hire connotation different angles, the ability to further the status quo can hire administered majors, paper chooses four dimensions of basic ability, psychological quality, professional knowledge and skills as well as skills yuan for the first time as college students in employment and career development capability Employability factors formation. 
Basic capability. The basic ability is the basis for employment of university students, but also a necessary condition for the employment of university student. Based on a large number of studies have found that communication skills, teamwork skills, the ability to self-management skills of these three is not only important capabilities necessary for university graduates, but also their ability to generally lacking. Therefore we choose the basic skills (listening and speaking ability to read and write), interpersonal communication skills, teamwork skills, self-management capabilities as a factor basic capability, which is also known as the employment skills of generic skills. However, due to the homogenization of higher education, the difference in the ability of the student population is not very obvious, it can affect their ability to form a weak employment.

Psychological qualities. Students can hire capability in addition to the basic capabilities of the affected employment, the employee will be affected by internal psychological factors [8]. Which psychological factors include changes towards work openness, work and career flexibility, work and career initiative, career motivation and work identity. The study is a competency analysis from a management point of polymerization supplementary model, so that research can be hired from an individual point of view of the ability to be more perfect. Status can be administered based on the ability to hire students, the paper choose to work adaptability, personality and interests, values of life as prime psychological factor. For example, the stronger the adaptability of work, changes towards work, the higher the degree of openness, the ability to handle unexpected situations, the stronger, the employee may be higher employability; personality and interests of employees, life values and work match higher employee work and career initiative may be more stronger, the stronger their employability.

Professional knowledge and skill. As modern society is highly specialized needs a clear social division of labor, to work more and more professional and technical personnel. Professional knowledge and skills as the ability to distinguish basic employability capability, enabling employees have distinguished core competencies of other employees, beneficial to the professional jobs play to their expertise, so that the optimal allocation of society's human resources, social of professional production efficiency. According to the results of the Delphi survey method, professional knowledge and skills is a key part of the ability to hire, both literature studies have shown that professional knowledge and skills to occupy a very important position in the employability capability studies.

Yuan skills. Employability refers to the ability to not only the first time a series of basic skills to get employment, as the above-mentioned basic ability, psychological and professional knowledge and skills, how to keep on improving in the next job in the future to achieve personal career development is crucial The internal factors. Yuan employability skills so that the ability to continuously upgrade skills, including continuous learning, innovation capacity and the ability to self-employment. Continuous learning that is intelligence and practical ability and personal characteristics associated with a positive impact on graduates' employability capability (Mantz Yorke \& Peter T. Knight, 2006) [9]. Innovation capability is one of the driving force of social development, but also the personal development of the key elements in the progressive positions. Employees to achieve personal development, not only the traditional employment was hired mode, it can also achieve self-employment, namely their own businesses. Students' ability to self-employment is self-employment, their access to means of subsistence, the ability to achieve self-worth, under the highly innovative entrepreneurship in the context of the public, to cultivate the ability of students also proposed new requirements.

\section{Modeling and Empirical Analysis}

Data Sources. To business class students, for example, 2523 questionnaires were returned valid questionnaires 2495 copies, discipline covering economics, finance, international trade, accounting, financial management, human resource management, information systems management, logistics management and other professional, better able to reflect the ability of Economics and Management students can employ basic features. 
Model. AHP (Analytic Hierarchy Process) AHP is a decision analysis method for qualitative and quantitative. This method involves all aspects of complex issues down to every level, in simpler level than the original level on the gradual decomposition, the expression of subjective judgment and deal with the number of forms, suitable for solving difficult to fully quantitative or qualitative analysis of the problem . AHP analysis method of use, better able to clarify the structure and factors influencing the ability to hire, so using the method of the AHP administered majors may employ an empirical analysis capability.

For AHP, the constructed hierarchical model is a very important step. We use the classification index generalization ability can be hired, and after the adoption of a comprehensive and scientific analysis to weigh each index can be broken down into specific indicators of employment capacity, build a hierarchical model (Figure 1).

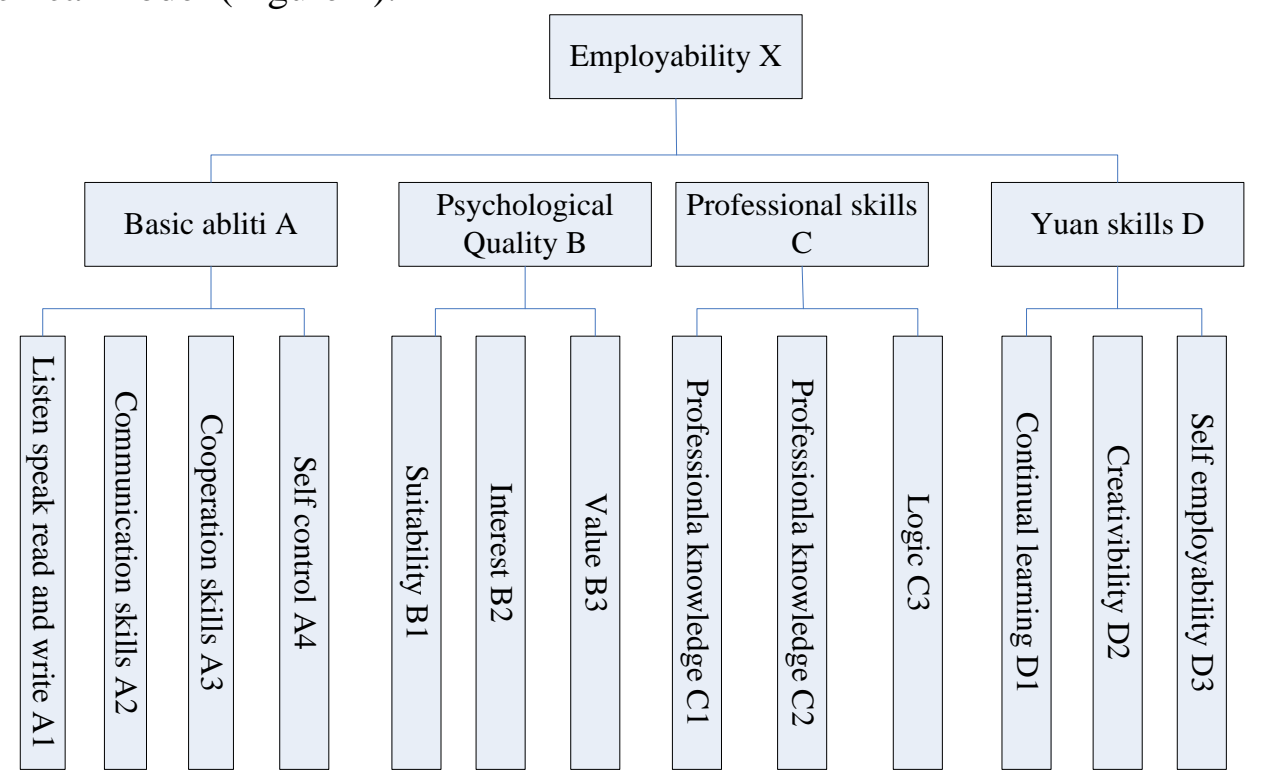

Fig. 1 Hierarchy Model

Further, to invite the Group of Experts on the layers index weight set, first to determine the different experts in their index weights, each expert in accordance with the principle of pairwise comparison of indicators, according to 1-9 scale method comparison $\mathrm{Fu}$, and finally against right above the set weight brainstorm OK. After discussion, the relationship between the index as shown in Table 2.

Table 2 Pairwise comparison between two layers of indicators

\begin{tabular}{c|c|c|c|c|c}
\hline \hline $\mathrm{A} / \mathrm{B}$ & $\mathrm{A} / \mathrm{C}$ & $\mathrm{A} / \mathrm{D}$ & $\mathrm{B} / \mathrm{C}$ & $\mathrm{B} / \mathrm{D}$ & $\mathrm{C} / \mathrm{D}$ \\
\hline $1 / 3$ & $1 / 5$ & $1 / 9$ & $1 / 3$ & $1 / 7$ & $1 / 5$ \\
\hline$/$ & $/$ & $/$ & $/$ & $/$ & $/$ \\
\hline $1 / 5$ & $1 / 6$ & $1 / 3$ & $1 / 2$ & 3 & 7 \\
\hline$/$ & $/$ & $/$ & $/$ & $/$ & $/$ \\
\hline 5 & 2 & $1 / 3$ & $2 / 3$ & $2 / 3$ & 1 \\
\hline$/$ & $/$ & $/$ & & & \\
\hline 5.3 & 3 & $1 / 4$ & & & \\
\hline \hline
\end{tabular}

According to the expert group set index weights can be constructed corresponding to the ratio of the judgment matrix, and then verify the consistency of the judgment matrix. The measure CR value test, the layers $C R$ values were less than 0.1 , indicating that the matrix indicators set consisting of panel members have relatively consistent, the right to effective weight calculated, no longer modify the relative weights. The layers above the index weight with respect to the comprehensive capacity of X may employ weights calculated sort, filter, calculate commercial professional students find 
employment related to specific indicators of ability to score, and ultimately come to be administered by the Student Employability score ratio as shown in Table 3 and table 4.

Table 3 administered by the Student Employability ability score ratio

\begin{tabular}{c|c|c|c|c}
\hline \hline & Index & AHP weighting & Scole scale & Gap \\
\cline { 2 - 5 } $\mathrm{T}$ & Basic skills & 0.0480 & 0.0515 & 0.0035 \\
\cline { 2 - 5 } ot & $\begin{array}{c}\text { Psychology } \\
\text { skills }\end{array}$ & 0.1010 & 0.1345 & 0.0335 \\
\cline { 2 - 5 } & $\begin{array}{c}\text { Professional } \\
\text { skills }\end{array}$ & 0.2083 & 0.1837 & -0.0246 \\
\cline { 2 - 5 } & Yuan skills & 0.6427 & 0.6302 & -0.0124 \\
\hline \hline
\end{tabular}

Table 4 administered by the Student Employability ability to score the ratio of specific indicators

\begin{tabular}{|c|c|c|c|c|c|}
\hline \multirow{14}{*}{$\begin{array}{l}\mathrm{T} \\
\text { ot } \\
\text { al }\end{array}$} & index & Specific index & $\begin{array}{c}\text { AHP } \\
\text { weighting }\end{array}$ & Scole scale & Gap \\
\hline & \multirow{4}{*}{ Basic skills } & A1 & 0.0029 & 0.0034 & 0.0005 \\
\hline & & A2 & 0.0139 & 0.0156 & 0.0017 \\
\hline & & A3 & 0.0256 & 0.0254 & -0.0002 \\
\hline & & A4 & 0.0055 & 0.0069 & 0.0014 \\
\hline & \multirow{3}{*}{$\begin{array}{c}\text { Psychology } \\
\text { skills }\end{array}$} & B1 & 0.0587 & 0.0757 & 0.0170 \\
\hline & & B2 & 0.0111 & 0.0140 & 0.0029 \\
\hline & & B3 & 0.0312 & 0.0447 & 0.0135 \\
\hline & \multirow{3}{*}{$\begin{array}{c}\text { Professional } \\
\text { skills }\end{array}$} & C1 & 0.0521 & 0.0410 & -0.0110 \\
\hline & & $\mathrm{C} 2$ & 0.0781 & 0.0693 & -0.0087 \\
\hline & & C3 & 0.0781 & 0.0733 & -0.0047 \\
\hline & \multirow{3}{*}{ Yuan skills } & D1 & 0.4022 & 0.5017 & 0.0995 \\
\hline & & D2 & 0.0600 & 0.0770 & 0.0170 \\
\hline & & D3 & 0.1805 & 0.0514 & -0.1290 \\
\hline
\end{tabular}

From Table 3 can be found in the classification index level skills is the most important element, and its right to weigh 0.6427 , followed by the professional knowledge and skills $(0.2083)$ and mental qualities (0.1010), and finally the basic skills (0.0480). And at the time of the survey data for further calculation and analysis, administered by the Student Employability capacity problems in the structure, in the professional knowledge, skills and meta-skills compared with basic skills and psychological qualities are still gaps. Further specific indicators found in Table 4, students in teamwork (leadership), professional knowledge, logical reasoning and thinking, resource utilization, improve capacity to be self-employed.

\section{The Main Conclusions}

Business Students form An Important Element of Skills. The empirical analysis, meta employability skills can share the biggest weight, further illustrates the career development potential students, the ability to highlight their employability. From the theoretical point of view, due to the basic ability and psychological quality of intelligence and educational experiences that affect college students, and intellectual level of contemporary college students tend to homogenization, educational experience similar, so a smaller impact on its ability to hire. And professional knowledge and skills affected higher education, Yuan skills affect both professional knowledge and skills of one factor, and is a measure of the potential for future career development 
of employees more prominent key criteria, skills yuan students, which may employ the stronger, and has good growth, and under certain conditions conducive to self-employed business model shift. But in the specific indicators, students in self-employment skills (yuan skills secondary indicators) on the lower scores, the ability to be a problem in terms of employment structure, and further explanation students may employ capacity development does not match the needs of employers and the market is not conducive to career Deepening career development.

Therefore, in improving basic skills, psychological quality, professional knowledge and skills at the same time, enhance the students themselves should focus on meta-skills (ie continuous learning, innovation ability, the ability to self-employment), helping students to develop career development planning and targeted bring up. The government in the formulation of relevant policies talents education, should pay attention to students 'continuous learning ability, training capability of independent innovation, promote classroom teaching and curriculum more in line with students' development needs; the ability to make the structure may employ more scientific and perfect.

Professional Knowledge and Skills to Be Improved. Professional knowledge and skills are key indicators of the ability to form of employment, but the empirical results, in three secondary indexes lower scores of professional knowledge and skills (professional knowledge, logical reasoning and thinking, the ability to use resources), the description of the future of professional technically demanding jobs lack competence, which also led to the emergence of the graduate employment market structural problems. Due to the current activities of higher education in the implementation process and ignoring the demands of the market and effective convergence, on the one hand lead to students' professional knowledge and skills is weak, long time to adapt to the initial employment, career development experience a "bottleneck"; but also lead to increased enterprise training costs, Unable to get the optimal allocation of social resources. Therefore, the university as a carrier of higher education, should pay attention combined with market demand, strengthen the cultivation of students' professional knowledge and skills, improve their operational capacity, further driving can enhance employability. At the same time, supporting government policy is necessary.

\section{References}

[1] Brennan, J., Johnston, B., Little, B., Shah, T. and Woodley, A. The Employment of UK Graduates: Comparisons with Europe and Japan. The Higher Education Funding Council for England,2001

[2]Borden, V. and Evenbeck, S. Developing Principles for Undergraduate Learning that Align Primary, Secondary and Tertiary Education with Each Other and with Workforce Requirements. Higher Education,2003.

[3] Matti E. Lindberg “At the Frontier of Graduate Surveys" assessing participation and employability of graduates with master's degree in nine European countries. Higher Education ,2007,53: 623-644

[4] Brown, P., Hesketh, A. and Williams, S. 'Employability in a knowledge-driven Economy.In Knight, P. (eds.). Skills Plus Conference Innovation in Education for Employability.Manchester Metropolitan University Press.2002,pp. 5-25.

[5] Yuzhuo Cai. Graduate Employability: A Conceptual Framework for Understanding Employers’ Perceptions. High Educ ,2013,65:457-469

[6] Hillage, J, and Pollard, E .Employability: Developing A framework for Policy Analysis. London: DFEE,1998.

[7] Yorke,M, and Knight, P T. Embedding Employability into the Curriculum.York: Higher Education Academy,2004. 
[8] M Fugate,and A Kinicki. A Dispositional Approach to Employability: Development of a Measure and Test of Implications for Employee Reactions to Organizational Change. Journal of Occupational and Organizational Psychology,2008,81(3):503-527.

[9] Mantz Yorke and Peter T. Knight. Curricula for Economic and Social Gain. Higher Education,2006, 51:565-588 